\title{
Ochrobactrum anthropi
}

National Cancer Institute

\section{Source}

National Cancer Institute. Ochrobactrum anthropi. NCI Thesaurus. Code C86620.

A species of aerobic, Gram-negative, rod shaped bacteria assigned to the phylum

Proteobacteria. This species is motile using peritrichous flagella, catalase, urease and oxidase positive, indole negative, grows on MacConkey's agar, nonpigmented, does not hydrolyze casein, Tween 20 , or T ween 80 , reduces both nitrate and nitrite, produces acid from glucose, arabinose, ethanol, fructose, rhamnose and xylose, and has broad spectrum antibiotic resistance. O. anthropi has been isolated from water sources in is associated with nosocomial infections. 